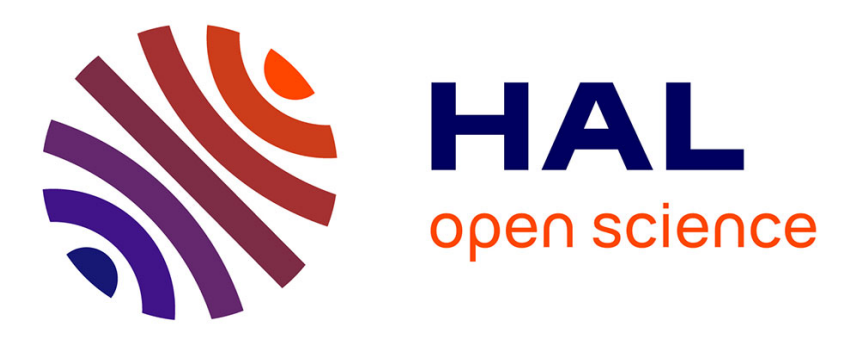

\title{
Effects Of Pre-Competitive Preparation Period On The Isokinetic Muscular Characteristics In World Class Handball Players
}

Olivier Maurelli, Pierre Louis Bernard, Romain Dubois, Said Ahmaidi, Jacques Prioux

\section{To cite this version:}

Olivier Maurelli, Pierre Louis Bernard, Romain Dubois, Said Ahmaidi, Jacques Prioux. Effects Of Pre-Competitive Preparation Period On The Isokinetic Muscular Characteristics In World Class Handball Players. Journal of Strength and Conditioning Research, 2019, 33 (4), pp.1065-1074. 10.1519/JSC.0000000000002199 . hal-01812546

HAL Id: hal-01812546

https://hal-univ-rennes1.archives-ouvertes.fr/hal-01812546

Submitted on 12 Jul 2018

HAL is a multi-disciplinary open access archive for the deposit and dissemination of scientific research documents, whether they are published or not. The documents may come from teaching and research institutions in France or abroad, or from public or private research centers.
L'archive ouverte pluridisciplinaire HAL, est destinée au dépôt et à la diffusion de documents scientifiques de niveau recherche, publiés ou non, émanant des établissements d'enseignement et de recherche français ou étrangers, des laboratoires publics ou privés. 
1

2

3

4 Effects Of Pre-Competitive Preparation Period On The Isokinetic Muscular 5 Characteristics In World Class Handball Players

6

7 Olivier Maurelli ${ }^{1}$, Pierre Louis Bernard ${ }^{2}$, Romain Dubois $^{3}$, Said Ahmaidi $^{1}$, Jacques Prioux $^{4}$ 8

$9 \quad{ }^{1}$ Exercise physiology and rehabilitation laboratory (EA-3300: APERE), Picardie Jules Verne 10 University, Amiens, France.

$11 \quad{ }^{2}$ Euromov, UFR APS, University Montpellier 1, France.

$12{ }^{3}$ Laboratory of Physical Activity, Health and Performance (EA 4445), University of Pau \& Pays 13 Adour, Tarbes, France

$14{ }^{4}$ Movement, Sport and Health laboratory (EA 1274), Faculty of sport science, Rennes, France.

Corresponding authors:

Olivier Maurelli

E-mail: oliviermaurelli@yahoo.fr

Tel: +33614407965 


\section{Abstract}

The aim of this study was to describe the effects of eight weeks of pre-competitive period preparation $(\mathrm{Pc} 2 \mathrm{P})$ on the isokinetic muscular characteristics in world-class handball players.

Nineteen male professional players (age: $26.6 \pm 5.4$ years) participated in the study. Two bilateral isokinetic tests of knee joint flexors (H; Hamstring) and extensors (Q; Quadriceps) were performed before and after Pc2P to determine the peak torque (PT), the mean power (MP) and the ratios (agonist/antagonist, dominant/non-dominant and combined). For the PT, $\mathrm{Q}$ at low angular velocity $\left(60^{\circ} . \mathrm{s}^{-1}\right)$ in concentric mode revealed no significant increase for the dominant nor non-dominant legs. For $\mathrm{H}$, results showed a significant increase for both legs ( $p$ $<0.001)$. At the higher angular velocity $\left(240^{\circ} \cdot \mathrm{s}^{-1}\right), \mathrm{Q}$ was significantly increased for the dominant $(p<0.005)$ and non-dominant legs $(p<0.002)$ as well as $\mathrm{H}$ for both sides $(p<$ 0.001). Eccentric mode $\left(30^{\circ} \cdot \mathrm{s}^{-1}\right)$ showed a significant increase for dominant $(p<0.005)$ and non-dominant legs $(p<0.01)$. For MP, results showed significant increase at low angular velocity $(p<0.003)$ and high angular velocity $(p<0.01)$ for both legs. In eccentric mode, values showed a significant increase following Pc2P for dominant $(p<0.001)$ and nondominant legs $(p<0.02)$. The ratios showed significant increase for the agonist/antagonist ratio (AAR) at $60^{\circ} \cdot \mathrm{s}^{-1}$ for dominant leg $(p<0.003)$ as well as the non-dominant leg $(p<0.01)$. At $240^{\circ} . \mathrm{s}^{-1}$ the values showed a significant difference for both side $(p<0.02)$. From an injury risk perspective, in addition to optimizing performance, these results demonstrated that eight weeks of Pc2P increased the maximum strength and muscle power of international handball players, even if the ratios of the knee joint muscles did not change during this period.

Key words: elite handball; muscular profile of the lower limbs; preseason period. 


\section{INTRODUCTION}

Handball is played by two teams of seven players on a court measuring 40 by 20 meters during matches of two periods lasting 30 minutes. The average actual play time is $52.36 \pm$ 5.92 minutes for an elite men's team (41) with field players moving for more than $60 \%$ of the total playing time with an average distance of $4370 \pm 702 \mathrm{~m}$ (44). Their activity consists of a succession of actions such as jumps, sprints, offensive and defensive duels, shooting, and changes of direction which are followed by random recoveries $(35,40,45)$. These actions place high neuromuscular demand on the body, primarily on the lower limbs, and are repeated throughout the match; therefore, they are critical to performance (35).

Actions like duels require the production of maximum strength, whereas others, such as explosive actions, require a high rate of strength development and power (27) with contraction times of less than $250 \mathrm{~ms}$ (2). Given the demand on the lower limb neuromuscular system, the investigation of knee muscle functioning adaptations in handball players is necessary (14). To assess these adaptations, several tests exist such as the one-repetition maximum (1-RM) test, vertical jump tests (squat jump or counter movement jump), electromyography assessments (EMG) and isokinetic testing. EMG and isometric test measurements from Thorlund et al. (51) have found that muscle and joint stress in elite handball players are side effects of fatigue following a game. Compared to others, the isokinetic dynamometer provides valid and reproducible measurements $(7,12)$ to assess knee joint strength $(13,34)$. Although the isokinetic device was initially utilized for muscular rehabilitation (11), it has become a reference for the exploration and research of strength as well as injury prevention in sports $(9,15,20,22,34)$. Few studies have used an isokinetic dynamometer in handball players. Gonzales-Ravé (26) and Holm (31) have analyzed muscular profiles in elite male and female handball players to study isokinetic strength in order to optimize performance (26) and to prevent the cruciate ligaments rupture, respectively 
(31). A handball season consists of two distinct periods : a pre-competitive preparation period (Pc2P) of six to eight weeks and a competition period of nine months $(10,28,29)$. Pc2P usually focuses on developing technical and tactical skills in addition to the physical qualities needed to optimize performance for the competitive period (6). Pc2P also provides insight into the repeated stresses on muscles, which occur throughout the season and result in fatigue setting in gradually (24). In team sports, few authors have studied Pc2P. Although certain studies have analyzed the physical and physiological changes in competitive soccer $(24,33,46)$ and rugby players $(6)$, few studies have referred to changes in isokinetic strength values in the lower limbs. Only Orchard et al. (43) specifically analyzed the changes in peak torque (PT) and the strength of quadriceps $(\mathrm{Q})$ and hamstrings $(\mathrm{H})$ in Australian soccer players. To date, no studies have investigated the effects of $\mathrm{Pc} 2 \mathrm{P}$ on muscle adaptations in world-class handball players. However, the monitoring of isokinetic strength and muscle power before and after Pc2P, through the measuring of PT and mean power (MP) of Q and $\mathrm{H}$, could be used to illustrate its effects in handball players and to reorient if necessary training methods during this time. Furthermore, the analysis of available dominant/non-dominant (DNDR), agonist/antagonist (AAR) and combined ratios (CR) would accurately assess the muscular characteristics of each player, permitting injury prevention. The aim of our study was then to analyze the effects of a Pc2P, with duration of eight weeks, on the isokinetic muscle profile of the lower limbs in world-class handball players. We hypothesized that Pc2P would be an appropriate period to develop the isokinetic muscular performance, allowing athletes to begin the competitive period with optimized strength and power levels. 


\section{METHODS}

\section{Experimental approach to the problem}

To achieve the purpose of our study, the handball players were monitored before and after Pc2P. All subjects were familiar with the isokinetic tests. Before and after Pc2P, these tests were always carried out at the same time of the day and in the same order for all the subjects. On the day of evaluation, after a standardized breakfast for all studied players, measurements of body mass and fat free mass were carried out. Afterwards, the subjects then performed an isokinetic test.

Pc2P lasted eight weeks and was organized to optimize performance at the end of this period (Figure 1). The cardio-respiratory function was the main focus of 16 sessions (17.8\% of the total volume) on the whole of Pc2P. The training included three separate phases (Table 1). The first phase, with a duration of two weeks, focused on aerobic capacity development (65-80\% of maximum heart rate (HRmax)) began (i) with continuous training sessions and (ii) ended with fartlek sessions. During the first phase, subjects performed three sessions per week. The second phase of cardio-respiratory training, with a duration of four weeks, focused on maximum aerobic power development ( 85 to $100 \%$ HRmax). This phase was based at the beginning on long and medium interval training and at the end on short interval training. During this phase, subjects performed two sessions per week. Finally, during the two-week third phase of cardio-respiratory training, subjects performed only one session of maximum sprint training with a short recovery. 
The technical and tactical training aspects of handball received the most attention with 46 sessions, accounting for $51.1 \%$ of the training volume of Pc2P. A psychomotor emphasis during these sessions allowed for the improvement of the general and specific motor skills of handball player (coordination, agility, lateralization, segmental dissociation). This focus represented 11 sessions for $12.2 \%$ of the total volume. Finally, muscle strengthening was also utilized during 17 sessions (Table 2), with $18.9 \%$ of the total training volume of Pc2P. During the first two weeks of training, focused on endurance of strength, the intensity of the lower limb strength training ranged from 40 to $60 \%$ of one-repetition maximum (1-RM). Three sessions per week were dedicated to this training. In the next phase of a duration of four weeks, focused on hypertrophy and maximal strength, the intensity of lower limb strength training intensities was 70 to $90 \%$ 1-RM. During this phase, players made two sessions per week. The number of sessions was deliberately limited to two per week, in order to account for the training load in handball, which emphasizes in particular the use of the lower body. In the final two-week phase, focused on power, players dedicated to weight training characterized by a intensity from 50 to $60 \% 1-\mathrm{RM}$ at the rate of two sessions per week.

$* * *$

TABLE 2 HERE

\section{Subjects}

Nineteen male handball players, either French or foreign and belonging to the professional league 1 (France), were recruited for the study. The players had a training experience (7.6 \pm 1.3 years) of the highest level of expertise in France. Mean values $( \pm S D)$ of age, height, weight and body fat were respectively $26.6 \pm 5.4$ years, $189.5 \pm 5.1 \mathrm{~cm}, 91.8 \pm$ $12.5 \mathrm{~kg}$ and $10.2 \pm 2.2 \%$. Inclusion criteria were the following: being a male and being under contract for a minimum of three years. The exclusion criteria were chronic or acute diseases 
of the knee and/or lower limbs and pain in the knee and/or lower limbs at testing, contraindicating maximal concentric and eccentric exercise. All subjects have written informed consent to participate in the experiment in accordance with the Declaration of Helsinki. The study protocols were approved by the Ethics Committee of the local university and were carried out in agreement with the head doctor and validated by the medical committee of the club.

\section{Procedures}

\section{Isokinetic tests}

Subjects were evaluated using a Biodex Isokinetic Dynamometer 3® System (Biodex Corporation, Shirley, NY) with gravity correction. Two bilateral tests of knee joint flexors $(\mathrm{H})$ and extensors $(\mathrm{Q})$ were performed before and after Pc2P in concentric and eccentric mode. The warm-up and set-up procedure for the subjects were the same prior to and following Pc2P. Before the tests, the subjects warmed-up on a cycle ergometer for five minutes by cycling against a load of 60 watts (W) at 90 rotations.min ${ }^{-1}$. This warm-up was followed by active dynamic stretching of the psoas, $\mathrm{Q}, \mathrm{H}$ and gastrocnemius muscles. The range of motion during the test was $70^{\circ}$, from $-10^{\circ}$ to $60^{\circ}$ angle, between the femur and the tibia to limit hamstring resistance during the extension. The length of the lever arm was individually determined, depending of the height of each players and the resistance pad was placed two fingers above the medial malleolus. The tests were carried out bilaterally in a sitting position with a hip flexion angle of $110^{\circ}$, a trunk and waist strap, and the upper limbs crossed on the trunk. Each subject was placed in a comfortable position that did not limit knee movement. The height and depth of the seat relative to the dynamometer's rotational axis and the length of the lever arm relative to the rotational axis were stored in the computer program 
(Biodex Medical, Inc.) to standardize the test's conditions. During testing, subjects were verbally encouraged by the same experimenter and gripped the sides of the seat for support.

Each test was preceded by a standardized warm-up of two sets of five repetitions at $60^{\circ} . \mathrm{s}^{-}$ ${ }^{1}$ in concentric mode separated by one minute of recovery, following the three minutes of the initial cycling warm-up. The protocol started with an evaluation in the concentric/concentric modes on the dominant leg, beginning with a series of five repetitions at $60^{\circ} . \mathrm{s}^{-1}$, followed by one minute of recovery, then a new series of five repetitions at $240^{\circ} . \mathrm{s}^{-1}$. After one minute of recovery, evaluation of $\mathrm{H}$ at $30^{\circ} . \mathrm{s}^{-1}$ in eccentric mode concluded the first part of the test. During the following five-minute recovery, the subjects were set up for evaluation of the nondominant leg following the same procedure (47).

The values of PT and the MP, expressed in absolute values and normalized by body weight, were used to calculate DNDR and AAR at $60^{\circ} \cdot \mathrm{s}^{-1}$ and $240^{\circ} \cdot \mathrm{s}^{-1}$ in concentric mode. In addition, the evaluation in eccentric mode allowed us to calculate $\mathrm{CR}$ from the $\mathrm{H}$ values measured at $30^{\circ} . \mathrm{s}^{-1}$ in eccentric mode and the $\mathrm{Q}$ values measured at $240^{\circ} . \mathrm{s}^{-1}$ in concentric mode.

Testing one-repetition maximum (1-RM)

The one-repetition maximum test was measured after a standardized warm-up, which began with cardio-respiratory activation (aerobic capacity training at 70-75\% of HRmax) and then an articular mobilization of lower limbs (ankles, knees and hips). Subsequently, subjects began with two sets of $8-10$ repetitions at 50\% and $60 \%$ of 1-RM. Following this, subjects then performed successive 1-RM starting at about $75 \%$ of 1-RM and increased by $5 \%$ until reaching 1-RM. There was a rest interval of two to three minutes between the sets. Each subject had two attempts on the last performance to be executed (5). 
Testing maximal aerobic velocity (MAV)

The 20 meters shuttle run test was originally designed by Leger and Lambert (38). The test is based on the completion of repeated shuttle runs between two lines placed 20 meters apart. The running speed is incremental and dictated by audio signals from a tape recorder. The aim of the test is to complete as many shuttle runs as possible.

\section{Anthropometrics measures}

Body mass was measured with the players wearing light indoor clothing and no shoes, using a Tanita Body Composition Analysis (TBF-3000) (Tanita Corporation, Tokyo, Japan). Percentage of fat mass was estimated from four skinfolds thicknesses (biceps, triceps, subscapular, and supra-iliac), according to the method of Durnin and Rahaman (19). Fat free mass (FFM) was estimated as the difference between measured body mass and estimated body fat.

\section{Statistical analyses}

All data is presented as means \pm standard deviation (SD). After conducting a test of normality, the non-parametric Wilcoxon test for paired data was used to analyze the influence of Pc2P on PT, MP, DNDR, AAR and CR. The significance level was set at $p<0.05$. When significant differences were found, effect size (ES) was assessed from the Cohen's d. ES of 0.20-0.60, 0.61-1.19 and $\geq 1.20$ considered small, moderate and large respectively (32).

\section{RESULTS}

Peak torque

In concentric mode at $60^{\circ} . \mathrm{s}^{-1}$, the comparison of PT before and after Pc2P showed no significant difference in $\mathrm{Q}$ for the dominant and non-dominant legs. For H, PT increased significantly for both legs $(p<0.001)$. At $240^{\circ} . \mathrm{s}^{-1}$, the results showed that $\mathrm{Q}$ was significantly 
increased for the dominant $(p<0.005)$ and non-dominant legs $(p<0.002)$ as well as $\mathrm{H}$ for both sides $(p<0.001)$. In eccentric mode at $30^{\circ} . \mathrm{s}^{-1}$, results showed a significant increase for dominant $(p<0.005)$ and non-dominant legs $(p<0.01)$ (Figure 2). The Cohen's d. ES were 0.35 (small) in $\mathrm{H}$ for dominant and -0.25 (small) for non-dominant legs at $60^{\circ} . \mathrm{s}^{-1}$. At $240^{\circ} . \mathrm{s}^{-1}$, ES were -0.27 (small) and -0.34 (small) respectively for Q for dominant and non-dominant legs. For H, ES were -0.48 (small) for dominant and -0.44 (small) for non-dominant legs. At $30^{\circ} . \mathrm{s}^{-1}$ in eccentric, for $\mathrm{H}$, ES were -0.27 (small) for dominant and -0.21 (small) for nondominant leg.

\section{Mean power}

In concentric mode at $60^{\circ} . \mathrm{s}^{-1}$ and $240^{\circ} . \mathrm{s}^{-1}$ our results showed a significant increase of $\mathrm{Q}$ for the dominant side $(p<0.003)$ and non-dominant side $(p<0.001)$. For $\mathrm{H}$, the values showed a significant increase for dominant side $(p<0.001)$ at $60^{\circ} . \mathrm{s}^{-1}$ and $240^{\circ} . \mathrm{s}^{-1}$. For nondominant side, our results showed a significant increase $(p<0.003)$ at $60^{\circ} . \mathrm{s}^{-1}$ and $(p<0.01)$ at $240^{\circ} . \mathrm{s}^{-1}$. In eccentric mode, we observed a significant increase in MP of $\mathrm{H}$ for the dominant $(p<0.001)$ and non-dominant legs $(p<0.02)$ (Figure 3). At $60^{\circ} \cdot \mathrm{s}^{-1}$ the Cohen's d. ES were 0.26 (small) in Q for dominant leg and -0.24 (small) for non-dominant leg. For H, ES were 0.30 (small) for dominant and -0.14 (small) for non-dominant leg. At $240^{\circ} . \mathrm{s}^{-1}$, ES were -0.24 (small) for Q for dominant leg and -0.23 (small) for non-dominant leg. For H, ES were -0.29 (small) for the dominant leg and -0.17 (small) for the non-dominant leg. At $30^{\circ} . \mathrm{s}^{-1}$ in eccentric, for H, ES were -0.29 (small) for dominant leg and -0.17 (small) for non-dominant leg. 
Dominant/non-dominant, agonist/antagonist and combined ratios

At $60^{\circ} . \mathrm{s}^{-1}$ and $240^{\circ} . \mathrm{s}^{-1}$, the results for DNDR in concentric mode showed no

***

TABLE 3 HERE

$* * *$

\section{DISCUSSION}

This study set out to investigate the influence of $\mathrm{Pc} 2 \mathrm{P}$ on the isokinetic muscular characteristics of the knee joint in world-class handball players. The results showed a significant impact of Pc2P on the development of MP in Q and $\mathrm{H}$ in concentric mode for the two velocities ( 60 and $\left.240^{\circ} . \mathrm{s}^{-1}\right)$ and for both legs. The Pc2P effects were slightly more limited in $\mathrm{Q}$, since no increase in PT was observed in concentric contraction at $60^{\circ} . \mathrm{s}^{-1}$ for the dominant and the non-dominant leg.

These results can be explained in different ways. Firstly, the duration of Pc2P (eight weeks) appeared to be sufficient to induce a significant improvement in the majority of strength and power values of $\mathrm{H}$, and to a lesser extent of $\mathrm{Q}$. Secondly, these results may be explained by the Pc2P training, as a relatively large share of training sessions (18.9\%) were dedicated to building muscle. The gain in strength and power after Pc2P may also be explained by the muscle deconditioning in these world-class handball players during the five 
weeks of training interruption preceding Pc2P. Indeed, Marquez and Badillo (39) indicated a significant decrease in the strength of handball throws after seven weeks of training interruption and Andersen et al. (3) reported lower isokinetic strength in sedentary adults after a 12-week period of inactivity. The significant increases noted above were observed despite the need to manage the optimal development of both strength and endurance qualities alongside technical and tactical sessions $(51.1 \%)$ as well as preparation matches $(\mathrm{n}=8)$ that coincided with Pc2P. The effects of the concurrent development of these two major muscle functional qualities have also been the subjects of several studies. Some studies have shown that strength gains are inhibited by the addition of endurance training sequences $(18,30,48,50)$, mainly due to a physiological interference between two signaling pathways. One pathway stimulates growth factors like IGF-1, thereby optimizing protein synthesis and thus the increase in strength and hypertrophy: mTOR (mammalian/mechanistic target of rapamycin). The other stimulates the metabolism of carbohydrates and fatty acids: AMPK (metabolic activated protein kinase) (23), which inhibits mTOR and thus limits these training responses $(17,42)$. To limit the negative effects of concurrent training in strength and endurance, a recent literature review (25) recommended not exceeding two to three endurance sessions per week, avoiding long-term running, and always placing the power session before the endurance session. These potential interferences may explain in part the lack of significant change in the low angular velocity strength values for Q and not for $\mathrm{H}$. $\mathrm{H}$ was not impacted by these interferences thanks to regular sessions that included muscle strengthening of the posterior chain, and also by multiple positions of knee flexion found in handball.

The reduction of the number of strengthening exercises involving the anterior muscle chain in the thighs might be another possible explanation. We adapted the session contents and indirectly favored limited loading on Q, as this muscle group is already highly solicited in handball. The results are consistent with the previous studies. Reilly and Thomas (46) showed 
that a six-week Pc2P did not significantly improve strength in the knee joint muscles of soccer players, while Dudley and Djamil (18) observed a significant improvement in muscle strength in the knee joint in a population of trained men and women, but only at high angular velocity.

Pc2P is a complex period, and training programs are dictated by the demands of the sport. Physical qualities will be developed according to the priorities set. Yet overall, too few studies have investigated the Pc2P influence on knee strength gains (33) and further studies are needed. The significant increase in PT of $\mathrm{H}$ and Q at high angular velocity $\left(240^{\circ} \cdot \mathrm{s}^{-1}\right)$ can be explained by the repetition of explosive actions in handball (35). Compared with other team sports such as rugby, handball training includes a high number of different types of practice sessions (including technical and tactical play as well as game on a half-sized court) from the first week of Pc2P for players to improve their specific motors skills, such as passing and shooting. A professional team, mainly composed of international players, participated in 46 handball-specific sessions during Pc2P. In each session, many actions were executed at high intensity. The study carried out by Behm and Sale (8) found that the greatest strength gains were observed at velocities close to the training velocity. These results observed at high intensity reported that the significant effects on the isokinetic strength expressed at high angular velocity are due to the combination of strength training sessions and specific activity sessions of Pc2P (21). The results of our study were, however, more pronounced for the power values, which are in agreement with the training program (Table 1). During Pc2P, the objective was primarily to develop power indices and not maximal strength. This objective is in agreement with the need for movements at high angular velocities in most team sports practiced at the highest level. These movements are systematically repeated during matches, especially during sprints involving the knee joint at velocities in the range of $600-700^{\circ} . \mathrm{s}^{-1}$ (48). Regular high-speed segmental movements during handball activity support the motor 
adaptations at high velocities (21).

Pc2P is also a key period for strengthening vulnerable muscle groups. In order to prevent injury, $\mathrm{H}$ strengthening is systematically included in the strength-building sessions. This may explain the significant increase in PT of $\mathrm{H}$ at low angular velocity $\left(60^{\circ} . \mathrm{s}^{-1}\right)$. Furthermore, the significant increase in PT found at $30^{\circ} . \mathrm{s}^{-1}$ in eccentric mode was likely due to the development of injury prevention routines during this period. Indeed, the mechanical needs of this muscle group, regularly constrained by the stretching phase during sports practice, constitute one of the justifications for the observed improvements in eccentric mode. The constant need to optimize performance necessarily requires consideration of individual muscular characteristics and the assessment of how training influences muscle balance in the knee $(1,4,13,34,37)$. For DNDR, our results showed no significant changes. In the early phase of Pc2P, the ratio was already good, as demonstrated by a value close to 1.0 . It is therefore normal that the ratio would not change in eight weeks. These results also indicate that handball does not significantly affect major imbalances between the dominant and nondominant legs, even though handball players preferentially use the same leg when throwing. For the notion of agonist/antagonist balance, represented by the AAR, at $60^{\circ} . \mathrm{s}^{-1}$ for dominant leg $(p<0.003)$, non-dominant leg $(p<0.01)$ and at $240^{\circ} . \mathrm{s}^{-1}$ for both side $(p<0.02)$, the Pc2P favors a significant increase. Nevertheless, the little changes near the reference values, from 0.6 at low velocity to 0.7 at high velocity, limits the interpretation of the data $(14,20)$. Duration of Pc2p appears too short to expect changes in muscle balance or lead to physiological adaptations.

Regarding these two ratios, some authors $(14,16,36)$ have critiqued their use due to their distance from functional reality, and propose the use of CR. This last ratio measures the maximum strength of $\mathrm{Q}$ at high angular velocity $\left(240^{\circ} \cdot \mathrm{s}^{-1}\right.$ in concentric mode) in relation to that of $\mathrm{H}$ at low angular velocity $\left(30^{\circ} . \mathrm{s}^{-1}\right.$ in eccentric mode), which could be more useful to 
prevent damage of $\mathrm{H}$. Analysis reveals absence of significant changes and maintenance at a value slightly greater than 1.0 (Table 2). However, the results were satisfactory and suggest that $\mathrm{Pc} 2 \mathrm{P}$ is not necessarily suitable for rebalancing ratios in order to prevent injury for several reasons. Physical training in Pc2P is mainly focused on developing strength and endurance. Given the high proportion of training time assigned to technical and tactical components $(51.1 \%)$, which are essential factors of handball performance, it would be difficult to further increase the overall training load without the risk of overreaching or overtraining. This finding makes it problematic for an individualized treatment goal of achieving a balanced muscle mass. In addition, the Pc2P period is perhaps not long enough to efficiently impact muscle imbalances, even though the program regularly includes prevention exercises.

Our results show that eight weeks of Pc2P significantly increased isokinetic PT, except for PT at $60^{\circ} . \mathrm{s}^{-1}$ and MP for the dominant and the non-dominant sides for the two velocities of $60^{\circ} . \mathrm{s}^{-1}$ and $240^{\circ} . \mathrm{s}^{-1}$ in world-class handball players. The ratios did not change during this period, except for some AAR ratio, thus the study shows that eight weeks of Pc2P does not lead to a major imbalance of the knee joint muscles in world-class handball players.

\section{Limitation of study}

One limitation of this study is that muscle groups were tested using an isokinetic dynamometer with a monoarticular approach, while sports are played in a closed system, suggesting that several muscle groups contribute to athletic performance. Moreover, it was impossible to establish a control group with regard to the elite level of the team (6).

\section{PRACTICAL APPLICATIONS}

To increase the efficiency of the training program and optimize performance in the season, the head coach of strength and conditioning will have to multiply the sessions 
dedicated to the development of the strength and muscular power during this Pc2P. The study by Silva et al. (49) show, in professional soccer players, with an important initial level of strength and muscular power, leads to a less-marked decrease of performance in the game. Given these observations it would be necessary that players start the season with their maximum capacity developed in order to tolerate the stress of a competitive season that usually runs for 9-10 months, with official matches played every week. Thereafter, the increasingly busy schedules do not allow for the maintenance of strength and muscular power. This has long been understood in rugby, which limits almost exclusively the first three weeks of Pc2P to physical work. In handball, there are several possibilities to consider in order to counteract this. In the absence of being able to lengthen the duration of Pc2P, it would be advantageous to modify the training program in volume and/or intensity. In order to optimize the Pc2P, it would be interesting to increase the number of practice sessions that are focused on maximal strength. For this reason, the organization of practice sessions initially planned (Table 2) for the first week of training to be dedicated to strength endurance, followed by a week of hypertrophy, followed directly by three weeks of maximal strength. These final three weeks could be followed by two weeks of power development by the method of contrasting loads (light-heavy) to maintain the strength levels for a longer period of time. Finally, the last week would focus exclusively on the development of explosivity. This new programming strategy would allow for five weeks of maximum strength training instead of the previously stated three weeks.

This study, which reveals Pc2P as an appropriate and measurable period, could guide the head coach of strength and conditioning, coaches of professional sports teams, and researchers to optimize the performance of professional players and consequently to better protect them from injuries acquired during the length of the sport's seasons, including the increase in quantity of competitions. 


\section{Acknowledgements}

The authors would like to thank the professional handball players for their

participation in this research. This study did not receive any financial support. None of the authors have any conflicts of interest. The results of the present study do not constitute endorsement by NSCR.

\section{References}

1. Aagaard, P, Simonsen, EB, Magnusson, SP, Larsson, B, and Dyhre-Poulsen, P. A new concept for isokinetic hamstring:quadriceps muscle strength ratio. Am J Sport Med 26: 231-37, 1998.

2. Aagaard, P, Simonsen, EB, Andersen, JL, Magnusson, P, and Dyhre-Poulsen, P. Increased rate of strength development and neural drive of human skeletal muscle following resistance training. J Appl Physiol 93: 1326, 2002.

3. Andersen, LL, Andersen, JL, Magnusson, SP, Suetta, C, Madsen, JL, Christensen, LR, and Aagaard, P. Changes in the human muscle strength-velocity relationship in response to resistance training and subsequent detraining. J Appl Physiol 99: 87-94, 2005.

4. Andrade, MDS, De Lira, CAB, De Carvalho, Koffes, F, Mascarin, NC, Bendito Silva, $\mathrm{AA}$, and Da Silva, AC. Isokinetic hamstrings to quadriceps peak torque ratio: the influence of sport modality, gender and angular velocity. J Sport Sci 30(6): 547-53, 2013.

5. Antonio, $\mathrm{J}$ and Ciccione, $\mathrm{V}$. The effects of pre versus post workout supplementation of creatine monohydrate on body composition and strength. J Int Soc Sports Nutr 10: 36, 2013.

6. Argus, CK, Gill, N, Keogh, J, Hopkins, WG, and Beaven, CM. Effects of short term pre-season training program on the body composition and anaerobic performance of professional rugby union players. J Sport Sci 28(6): 679-686, 2010.

7. Augustsson, J and Thomeé, R. Ability of closed and open kinetic chain tests of muscular strength to assess functional performance. Scan J Med Sci Sports 10(3): 16468, 2000.

8. Behm, DG, and Sale, DG. Velocity specificity of resistance training. Sports Med 15: 374-88, 1993.

9. Bernard, PL, and Amato, M. Influence of sport discipline and age on balance of the knee joint muscles. Sci Sport 24: 173-77, 2009.

10. Bresciani, G, Cuevas, MJ, Garatachea, N, Molinero, O, Almar, M, De Paz, JA, Marquez, S and Gonzalez-Gallego, J. Monitoring biological and psychological measures troughout an entire season in male handball players. Eur J Sport Sci 10(6): 377-384, 2010.

11. Calmels, P, and Minaire, P. A review of the role of the agonist/antagonist muscle pairs ratio in rehabilitation. Disabil Rehabil 17(6): 265-76, 1995. 
12. Croisier, JL, Forthomme, B, Namurois, MH, Vanderthommen, M, and Crielaard, JM. Hamstring muscle strain recurrence and strength performance disorders. Am J Sport Med 30(2): 199-203, 2002.

13. Croisier, JL, Malnati, M, Reichard, LB, Peretz, C, and Dvir, Z. Quadriceps and hamstring isokinetic strength and electromyographic activity measured at different ranges of motion: a reproductibility study. J Electromyogr Kinesiol 17(4): 484-92, 2007.

14. Croisier, JL, Ganteaume, S, Binet, J, Genty, M, and Ferret, JM. Strength imbalances and prevention of hamstring injury in professional soccer players: a prospective study. Am J Sport Med 36(8): 1469-75, 2008.

15. Davies, GJ, and Heiderscheit, BC. Reliability of the lido linea closed kinetic chain isokinetic dynamometer. J Orthop Sport Phys 25: 133-36, 1997.

16. Denot-Ledunois, S, and Fossier, E. Quadriceps femoris muscle relationships in isokinetic: concentric or eccentric. Sci Sport 9(3): 161-63, 1994.

17. Docherty, D, and Sporer, B. A proposed model for examining the interference phenomenon between concurrent aerobic and strength training. Sports Med 30(6): 38594. 2000.

18. Dudley, GA, and Djamil, R. Incompatibility of endurance and strength-training modes of exercise. J Appl Physiol 59(5): 1446-51, 1985.

19. Durnin, J, and Rahaman, M. The assessment of the amount of fat in the human body from measurements of skinfold thickness. Brit J Nutr 21: 681-89, 1967.

20. Dvir, Z. Isokinetics: Muscle testing, interpretation and clinical applications. 2nd ed. Edinburgh: Elsevier-Churchill Livingston, 2004.

21. Eniseler, N, Sahan, C, Vurgun, H, and Mavi, HF. Isokinetic Strength Responses to Season-long Training and Competition in Turkish Elite Soccer Players. J Hum Kinet 31: 159-68, 2012.

22. Feiring, DC, Ellenbecker, TS, and Dercheid, GL. Test-retest reliability of the Biodex isokinetic dynamometer. J Orthop Sport Phys 11: 298-300, 1990.

23. Foretz, M, Taleux, N, Giguas, B, Horman, S, Beauloye, C, Andreeli, F, Bertrand, L, and Viollet, B. Regulation of energy metabolism by AMPK: a novel therapeutic approach for the treatment of metabolic and cardiovascular diseases. Med Sci 22(4): 381-88, 2006.

24. Frisch, A, Urhausen, A, Seil, R, Croisier, JL, Windal, T, and Theisen, D. Association between preseason functional tests and injuries in youth football: a prospective followup. Scand J Med Sci Spor 21(6): 468-76, 2011.

25. Fyfe, JJ, Bishop, DJ, and Stepto, NK. Interference between concurrent resistance and endurance exercise: Molecular bases and the role of individual training variables. Sports Med 44: 743-62, 2014.

26. González-Ravé, JM Juárez, D, Rubio-Arias, JA, Clemente-Suarez, VJ, MartinezValencia, MA, and Abian-Vicen, J. Isokinetic leg strength and power in elite handball players. J Hum Kinet 8(41): 227-33, 2014.

27. Gorostiaga, EM, Granados, C, Ibanez, J, and Izquierdo, M. Differences in physical fitness and throwing velocity among elite and amateur male handball players. Int $J$ Sports Med 26: 225-32, 2005.

28. Gorostiaga, EM, Granados, C, Ibañez, J, González-Badillo, JJ, and Izquierdo, M. Effects of an entire season on physical fitness changes in elite male handball players. Med Sci Sport Exer 38(2): 357-66, 2006.

29. Granados, C, Izquierdo, M, Ibanez, J, Ruesta, M, and Gorostiaga, EM. Effects of an entire season on physical fitness in elite female handball players. Med Sci Sport Exer 40(2): 351-61, 2008. 
30. Hennessy, LC, and Watson, AWS. The interference effects of training for strength and endurance simultaneously. J Strength Cond Res 8(1): 12-19, 1994.

31. Holm, I, Fosdahl, MA, Friis, A, Risberg, MA, Myklebust, G, and Steen, H. Effect of neuromuscular training on proprioception, balance, muscle strength, and lower limb function in female team handball players. Clin J Sport Med 14(2): 88-94, 2004.

32. Hopkins, WG, Marshall, SW, Batterham, AM, and Hanin, J. Progressive Statistics for Studies in Sports Medicine and Exercise Science: Med Sci Sport Exer 41(1): 3-13, 2009.

33. Işlegen, C, and Akgün, N. Effects of 6 weeks pre-seasonal training on physical fitness among soccer players. In: Reilly, T, Lees, A, Davids, K, and Murphy, WJ. Science and football II. London: E \& FN Spon, 125-28, 1988.

34. Kannus, P. Isokinetic evaluation of muscular performance: implications for muscle testing and rehabilitation. Int J Sports Med 15: 11-18, 1994.

35. Karcher, C, and Buchheit, M. On-court demands of elite handball, with special reference to playing positions. Sports Med 44(6): 797-814, 2014.

36. Knapik, JJ, Bauman, CL, Jones, BH, Harris, JM, and Vaughan, L. Preseason strength and flexibility imbalances associated with athletic injuries in female collegiate athletes. Am J Sport Med 19: 76-81, 1991.

37. Kong, PW, and Burns, SF. Bilateral difference in hamstrings to quadriceps ratio in heathly males and female. Phys Ther Sport 11(1): 12-7, 2010.

38. Leger, LA and Lambert, J. A maximal multistage 20-m shuttle run test to predict VO2 max. Eur J Appl Physiol Occup Physiol 49(1): 1-12, 1982.

39. Marquez, MA, and Badillo, JJG. In season resistance training and detraining in professional team handball players. J Strength Cond Res 20(3): 563-571, 2006.

40. Michalsik, LB, Aagaard, P, and Madsen, K. Locomotion characteristics and match induced impairments in physical performance in male elite team handball players. Int $J$ Sports Med 34(7): 590-9, 2013.

41. Michalsik, LB, Madsen, K, and Aagaard, P. Physiological capacity and physical testing in male elite team handball. Int J Sports Med 55: 415-429, 2015.

42. Nader, GA. Concurrent strength and endurance training: from molecules to man. Med Sci Sport Exer 38(11): 1965-70, 2006.

43. Orchard, J, Mardsen, J, Lord, S, and Garlick, D. Preseason hamstring muscle weakness associated with hamstring muscle injury in Australian footballers. Am J Sport Med 25: 81-85, 1997.

44. Povoas, SCA, Seabra, AFT, Ascensao, AAMR, Magalhaes, J, Soares, JMC and Rebello, ANC. Physical and physiological demands of elite team handball. J Strength Cond Res 26(12): 3366-76, 2012.

45. Povoas, SCA, Ascensao, AAMR, Magalhaes, J, Seabra, AFT, Krustrup, P, Soares, JMC, and Rebello, ANC. Physiological demands of elite team handball with special reference to playing position. J Strength Cond Res 28(2): 430-42, 2014.

46. Reilly, T, and Thomas, V. Effects of a program of pre-season training on the fitness of soccer players. J Sport Med Phys Fit 17(4): 401-12, 1977.

47. Rochcongar, P. Isokinetic thigh muscle strength in sports: a review. Ann Readapt Med Phys 47(6): 274-81, 2004.

48. Sale, D, Jacobs, I, MacDougall, J, and Garner, S. Comparison of two regimens of concurrent strength and endurance training. Med Sci Sport Exer 22(3): 348-56, 1990.

49. Silva, JR, Magalhaes, JF, Ascensao, AA, Seabra, AF, and Rebelo, AN. Training status and match activity of professional soccer players thoughout a season. $J$ Strength Cond Res 27(1): 20-30, 2013. 
50. Tanaka, H, and Swensen, T. Impact of resistance training on endurance performance. Sports Med 25(3): 191-200, 1998.

51. Thorlund, JB, Michalsik, LB, Madsen, K, and Aagaard, P. Acute fatigue-induced changes in muscle Mechanical Properties and neuromuscular activity in elite handball players following a handball match. Scand J Med Sci Spor 18: 462-72, 2008.

\section{Figure titles}

Figure 1: Evolution of the volume training in $\mathrm{Pc} 2 \mathrm{P}$

Figure 2: Evolution of the peak torque in concentric and eccentric mode $\mathrm{Q}$ : Quadriceps ; H : Hamstrings ; 60QdomC : $60^{\circ} . \mathrm{s}^{-1}$ on Q concentric dominant side; 60QndomC : $60^{\circ} . \mathrm{s}^{-1}$ on $\mathrm{Q}$ concentric non-dominant side ; $60 \mathrm{HdomC}: 60^{\circ} . \mathrm{s}^{-1}$ on $\mathrm{H}$ concentric dominant side ; $60 \mathrm{HndomC}: 60^{\circ} \cdot \mathrm{s}^{-1}$ on $\mathrm{H}$ concentric non-dominant side ; 240QdomC : $240^{\circ} \cdot \mathrm{s}^{-1}$ on Q concentric dominant side ; 240 QndomC $: 240^{\circ} . \mathrm{s}^{-1}$ on Q concentric non-dominant side; $240 \mathrm{HdomC}: 240^{\circ} . \mathrm{s}^{-1}$ on $\mathrm{H}$ concentric dominant side; $240 \mathrm{HndomC}: 240^{\circ} . \mathrm{s}^{-1}$ on $\mathrm{H}$ concentric non-dominant side ; $30 \mathrm{HdomE}$ : $30^{\circ} . \mathrm{s}^{-1}$ on $\mathrm{H}$ eccentric dominant side ; $30 \mathrm{HndomE} \mathrm{:} 30^{\circ} . \mathrm{s}^{-1}$ on $\mathrm{H}$ eccentric non-dominant side ;

NS : No significant $; * *: p<0.01, * * *: p<0.001$.

Figure 3: Evolution of the mean power in concentric and eccentric mode

$\mathrm{Q}$ : Quadriceps ; H : Hamstrings ; 60QdomC: $60^{\circ} . \mathrm{s}^{-1}$ on Q concentric dominant side ; 60QndomC : $60^{\circ} . \mathrm{s}^{-1}$ on $\mathrm{Q}$ concentric non-dominant side ; $60 \mathrm{HdomC}: 60^{\circ} . \mathrm{s}^{-1}$ on $\mathrm{H}$ concentric dominant side ; $60 \mathrm{HndomC}: 60^{\circ} \cdot \mathrm{s}^{-1}$ on $\mathrm{H}$ concentric non-dominant side ; $240 \mathrm{QdomC}: 240^{\circ} \cdot \mathrm{s}^{-1}$ on Q concentric dominant side ; 240 QndomC $: 240^{\circ} . \mathrm{s}^{-1}$ on Q concentric non-dominant side ; $240 \mathrm{HdomC}: 240^{\circ} . \mathrm{s}^{-1}$ on $\mathrm{H}$ concentric dominant side; $240 \mathrm{HndomC}: 240^{\circ} . \mathrm{s}^{-1}$ on $\mathrm{H}$ concentric non-dominant side ; $30 \mathrm{HdomE}$ : $30^{\circ} . \mathrm{s}^{-1}$ on $\mathrm{H}$ eccentric dominant side ; $30 \mathrm{HndomE}: 30^{\circ} . \mathrm{s}^{-1}$ on $\mathrm{H}$ eccentric non-dominant side $* *: p<0.01 ; * * *: p<0.001$.

\section{Table titles}

Table 1: Organization of the endurance training program over the Pc2P

Pc2P : pre-competitive preparation period, AC : aerobic capacity ; MAP : maximum aerobic power ; AP : anaerobic power ; $\mathrm{r}=$ recovery between repetitions ; $\mathrm{R}=$ recovery between series.

Example : $(3 \times(8 \times 30 \mathrm{sec}), \mathrm{r}=30 \mathrm{sec}, \mathrm{R}=4 \mathrm{~min})$. It means that the subject had to run 3 series of 8 times $30 \mathrm{sec}$ composed of $30 \mathrm{sec}$ running at $90-100 \%$ of HRmax and $30 \mathrm{sec}$ passive recovery. The subject recovers passively 4 min between each series. Each session is repeated 2 times a week.

Table 2: Organization of the lower body strength training program over the Pc2P

$\mathrm{Pc} 2 \mathrm{P}$ : pre-competitive preparation period ; $1-\mathrm{RM}$ : one-repetition maximum ; rep : repetitions ; R : recovery.

Example : $(3 \times$ (12 rep x 60\% 1-RM), $R=1 \mathrm{~min} 30)$. It means that the subject had to realize 3 series of 12 repetitions at $60 \%$ 1-RM. The subject recovers passively 1 min 30 between each series. Each session is repeated 3 times a week.

Table 3: Ratios analyses

Pc2P: Pre-competitive preparation period ; $\mathrm{m}:$ mean; SD: Standard deviation; DNDR: Dominant/non-dominant ratio; AAR : Agonist/antagonist ratio ; CR : Combined ratio (eccentric at $30^{\circ} . \mathrm{s}^{-1}$ of $\mathrm{H}$ and concentric at $240^{\circ} . \mathrm{s}^{-1}$ of Q); RQ : Quadriceps ratio ; RH : Hamstrings ratio ; Dom : Dominant ; Ndom : Non-dominant ; P : significativity ; NS : No significant. 
Table 1: Organization of the endurance training program over the Pc2P

\begin{tabular}{|c|c|c|c|c|c|c|c|c|}
\hline \multicolumn{9}{|c|}{$\mathrm{Pc} 2 \mathrm{P}$} \\
\hline Weeks & 1 & 2 & 3 & 4 & 5 & 6 & 7 & 8 \\
\hline Objectives & \multicolumn{2}{|c|}{$\mathrm{AC}$} & \multicolumn{4}{|c|}{ MAP } & \multicolumn{2}{|c|}{ MAP-AP } \\
\hline Modality & $\begin{array}{l}\text { Continuous } \\
\text { training } \\
40-50 \mathrm{~min}\end{array}$ & $\begin{array}{c}\text { Fartlek training } \\
30-40 \text { min }(10 \\
\text { sec acceleration } \\
\text { every min) }\end{array}$ & $\begin{array}{l}8 \times 3 \text { min } \\
R=3 \text { min }\end{array}$ & $\begin{array}{c}(10-12) \times 1 \mathrm{~min} \\
\mathrm{R}=1 \mathrm{~min}\end{array}$ & $\begin{array}{c}3 \times(8 \times 30 \mathrm{se} \\
\mathrm{r}=30 \mathrm{sec} \\
\mathrm{R}=4 \mathrm{~min}\end{array}$ & $\begin{array}{l}(14 \times 15 \mathrm{sec}) \\
r=15 \mathrm{sec} \\
R=4 \mathrm{~min}\end{array}$ & $\begin{array}{c}2 \times(5 \times 30 \mathrm{sec}) \\
\mathrm{R}=4 \mathrm{~min}\end{array}$ & $\begin{array}{c}2 \times(6 \times 5 \mathrm{sec}) \\
\mathrm{r}=15 \mathrm{sec} \\
\mathrm{R}=8 \mathrm{~min}\end{array}$ \\
\hline Intensity & $65-70 \%$ HRmax & 75-80\% HRmax & $85-90 \%$ HRmax & 90-95\% HRmax & 90-100\% HRmax & 90-100\% HRmax & 90-100\% HRmax & HR not used \\
\hline Sessions & $\begin{array}{l}\text { Tuesday } \\
\text { Thursday } \\
\text { Saturday }\end{array}$ & $\begin{array}{l}\text { Tuesday } \\
\text { Thursday } \\
\text { Saturday }\end{array}$ & $\begin{array}{l}\text { Monday } \\
\text { Friday }\end{array}$ & $\begin{array}{l}\text { Mon } \\
\text { Frid }\end{array}$ & $\begin{array}{l}\text { Monday } \\
\text { Friday }\end{array}$ & $\begin{array}{l}\text { Monday } \\
\text { Friday }\end{array}$ & Tuesday & Tuesday \\
\hline
\end{tabular}

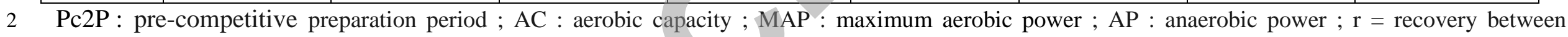
repetitions ; $\mathrm{R}=$ recovery between series

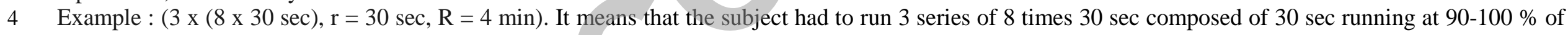

5 HRmax and $30 \mathrm{sec}$ passive recovery. The subject recovers passively 4 min between each series. Each session is repeated 2 times a week. 
Table 2: Organization of the lower body strength training program over the Pc2P

\begin{tabular}{|c|c|c|c|c|c|c|c|}
\hline \multicolumn{8}{|c|}{$\mathrm{Pc} 2 \mathrm{P}$} \\
\hline Weeks & 1 & 2 & 3 & 4 & 5 & 7 & 8 \\
\hline Objectives & \multicolumn{2}{|c|}{ Endurance of strength } & \multicolumn{3}{|c|}{ Hypertrophy and maximal strength } & \multicolumn{2}{|c|}{ Power } \\
\hline Modality & $\begin{array}{c}\text { Circuit Training } \\
30 \mathrm{~s} / \text { exercise } \\
4 \text { rounds } \\
\mathrm{R}=5 \mathrm{~min}\end{array}$ & $\begin{array}{c}3 \times 12 \text { rep } \\
\mathrm{R}=1 \min 30\end{array}$ & $\begin{array}{l}3 \times 10 \text { rep } \\
R=2 \text { min }\end{array}$ & $\begin{array}{c}4 \times \text { (6 to } 7 \text { ) rep } \\
\mathrm{R}=3 \mathrm{~min}\end{array}$ & $\mathrm{R}=4 \mathrm{n}$ & $\begin{array}{c}3 \times 6 \text { rep } \\
\mathrm{R}=2 \min 30\end{array}$ & $\begin{array}{c}3 \times 6 \text { rep } \\
\mathrm{R}=2 \min 30\end{array}$ \\
\hline $\begin{array}{l}\text { Training } \\
\text { Session }\end{array}$ & $\begin{array}{l}\text { - Squat } \\
\text { - Core stability } \\
\text { - Leg Curl } \\
\text { - Core stability } \\
\text { - Deadlift } \\
\text { - Core stability } \\
\text { - Leg Extension } \\
\text { - Core stability } \\
\text { - Swing Kettle } \\
\text { - Core stability }\end{array}$ & $\begin{array}{c}\text { - Squat } \\
\text { - Deadlift } \\
\text { - Step-up } \\
\text { - Lunge } \\
\text { - Swing Kettle }\end{array}$ & $\begin{array}{l}\text { - Hack squat } \\
\text { - R. Deadlift } \\
\text { - Step-up } \\
\text { - Lunge }\end{array}$ & $\begin{array}{c}\text { - Squat } \\
\text { - Deadlift } \\
\text { - Power clean }\end{array}$ & $\begin{array}{l}\text { - Squat } \\
\text { - Deadlift } \\
\text { - Step-up }\end{array}$ & $\begin{array}{c}\text { - Step-up } \\
\text { - Squat } \\
\text { - Clean and Jerk } \\
\text { - Snatch } \\
\text { - Plyometry body } \\
\text { weight }\end{array}$ & $\begin{array}{c}\text { - Step-up } \\
\text { - Squat } \\
\text { - Clean and Jerk } \\
\text { - Snatch } \\
\text { - Plyometry body } \\
\text { weight }\end{array}$ \\
\hline Intensity & $40 \% 1-\mathrm{RM}$ & $60 \% 1-\mathrm{RM}$ & $\% 1-\mathrm{RM}$ & $80 \% 1-\mathrm{RM}$ & $90 \% 1-\mathrm{RM}$ & $60 \% 1-\mathrm{RM}$ & $50 \% 1-\mathrm{RM}$ \\
\hline Sessions & $\begin{array}{l}\text { Monday } \\
\text { Wesdneday } \\
\text { Friday }\end{array}$ & $\begin{array}{l}\text { Monday } \\
\text { Wesdneday } \\
\text { Friday }\end{array}$ & $\begin{array}{l}\text { Monday } \\
\text { Thursday }\end{array}$ & $\begin{array}{l}\text { Monday } \\
\text { Thursday }\end{array}$ & $\begin{array}{l}\text { Monday } \\
\text { Thursday }\end{array}$ & $\begin{array}{l}\text { Monday } \\
\text { Thursday }\end{array}$ & $\begin{array}{l}\text { Monday } \\
\text { Thursday }\end{array}$ \\
\hline
\end{tabular}


Table 3 : Ratios analysis

\begin{tabular}{|c|c|c|c|c|c|c|c|c|c|c|c|}
\hline \multicolumn{6}{|c|}{$\begin{array}{c}\text { Concentric } \\
\left(60^{\circ} \cdot \mathrm{s}^{-1}\right)\end{array}$} & \multicolumn{4}{|c|}{$\begin{array}{c}\text { Concentric } \\
\left(240^{\circ} \cdot \mathrm{s}^{-1}\right)\end{array}$} & \multirow{2}{*}{\multicolumn{2}{|c|}{ CR }} \\
\hline & & \multicolumn{2}{|c|}{ DNDR } & \multicolumn{2}{|c|}{ AAR } & \multicolumn{2}{|c|}{ DNDR } & \multicolumn{2}{|c|}{ AAR } & & \\
\hline & & $\mathrm{RQ}$ & RH & Dom & Ndom & RQ & $\mathrm{RH}$ & Dom & Ndom & Dom & Ndom \\
\hline \multirow{2}{*}{$\begin{array}{c}\text { Before } \\
\text { Pc2P }\end{array}$} & \multirow{2}{*}{$\begin{array}{c}\mathrm{m} \\
( \pm) \\
\mathrm{SD}\end{array}$} & 1.04 & 1.01 & 0.57 & 0.6 & 1 & 1.01 & 0.68 & 0.68 & 1.05 & 1.02 \\
\hline & & 0.15 & 0.19 & 0.09 & 0.13 & 0.15 & 0.1 & 0.1 & 0.12 & 0.24 & \\
\hline \multirow{3}{*}{$\begin{array}{l}\text { After } \\
\text { Pc2P }\end{array}$} & \multirow{2}{*}{$\begin{array}{c}\mathrm{m} \\
( \pm) \\
\mathrm{SD}\end{array}$} & 1.03 & 1.01 & 0.6 & 0.61 & 0.99 & 1.01 & 0.72 & 0.7 & 1.06 & \\
\hline & & 0.11 & 0.16 & 0.09 & 0.11 & 0.14 & 0.1 & 0.07 & 0.12 & 0.21 & \\
\hline & $P$ & NS & NS & 0.003 & 0.01 & NS & NS & 0.02 & 0.02 & NS & \\
\hline
\end{tabular}

$P c 2 P$ : Pre-competitive preparation period ; $m$ : mean ; SD : Standard deviation ; DNDR :

Dominant/non-dominant ratio ; AAR : Agonist/antagonist ratio ; CR : Combined ratio (eccentric at $30^{\circ} . \mathrm{s}^{-1}$ of $H$ and concentric at $240^{\circ} . \mathrm{s}^{-1}$ of $Q$ ) ; $R Q$ : Quadriceps ratio; $R H$ : Hamstring ratio ; Dom : Dominant ; Ndom : Non-dominant ; $P$ : significativity ; NS : No 
1 Figure 2. Evolution of the peak torque in concentric and eccentric mode

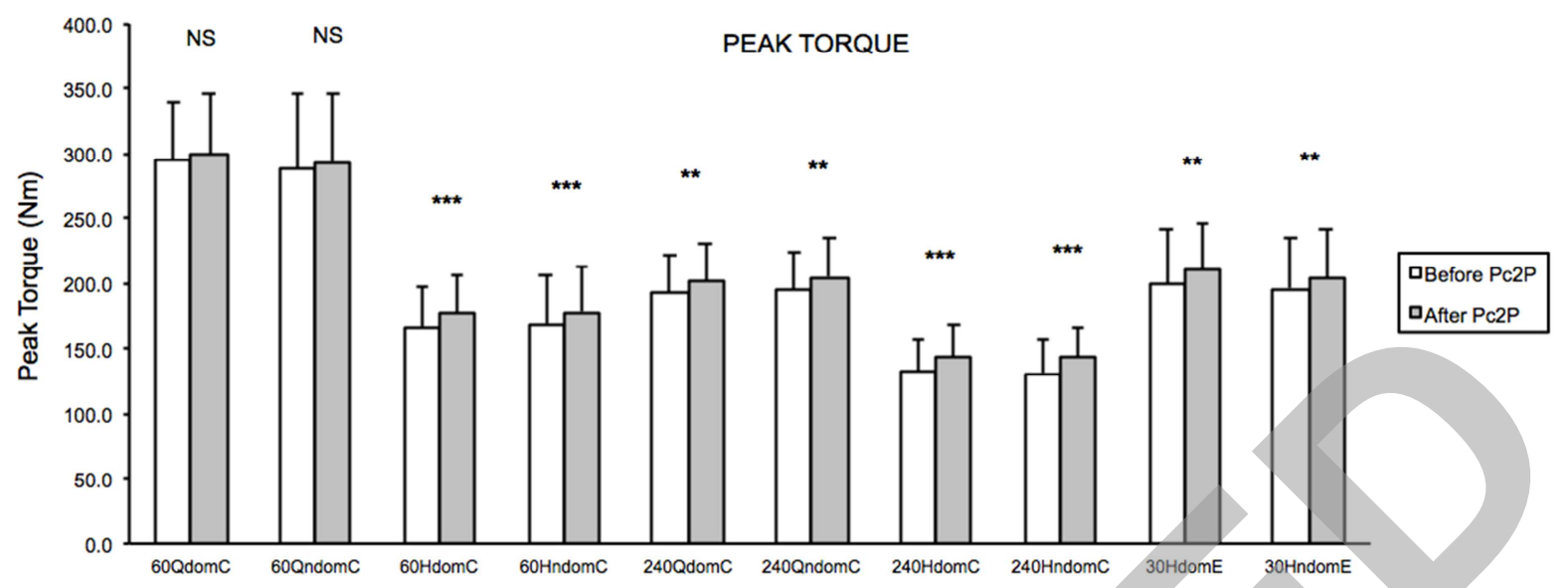

$Q:$ Quadriceps ; H : Hamstrings ; 60QdomC : $60^{\circ} . \mathrm{s}^{-1}$ on $Q$ concentric dominant side ; $60 Q$ ndom $C: 60^{\circ} . \mathrm{s}^{-1}$ on $Q$ concentric non-dominant side; $60 \mathrm{HdomC}: 60^{\circ} . \mathrm{s}^{-1}$ on H concentric dominant side; $60 H$ ndom $C: 60^{\circ} . s^{-1}$ on H concentric non-dominant side ; $240 Q d o m C$ : $240^{\circ} . s^{-1}$ on $Q$ concentric dominant side; $240 Q$ ndom $C: 240^{\circ} . s^{-1}$ on $Q$ concentric nondominant side ; $240 H$ dom $C: 240^{\circ} . s^{-1}$ on H concentric dominant side ; 240 HndomC $: 240^{\circ} . s^{-1}$ on $H$ concentric non-dominant side ; $30 H d o m E: 30^{\circ} . \mathrm{s}^{-1}$ on H eccentric dominant side ; $30 H$ ndomE $: 30^{\circ} . s^{-1}$ on H eccentric non-dominant side ; NS : No significant ; ** $: p<0.01$; $* * *: p<0.001$. 
1 Figure 3. Evolution of the mean power in concentric and eccentric mode MEAN POWER

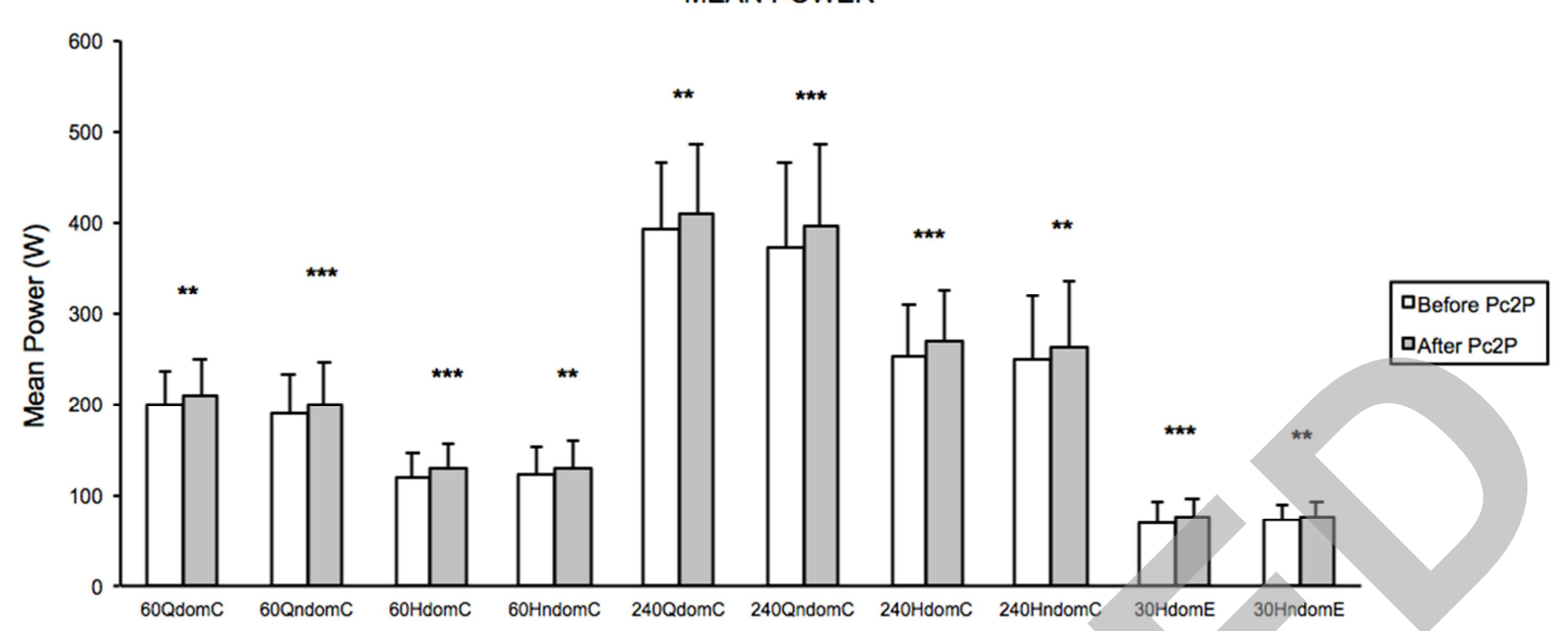

$Q:$ Quadriceps ; H : Hamstrings ; 60QdomC: $60^{\circ} . s^{-1}$ on Q concentric dominant side ; $60 Q$ ndom $C: 60^{\circ} . s^{-1}$ on $Q$ concentric non-dominant side; $60 \mathrm{HdomC}: 60^{\circ} . \mathrm{s}^{-1}$ on H concentric dominant side; 60HndomC : $60^{\circ} . \mathrm{s}^{-1}$ on H concentric non-dominant side; $240 Q$ domC : $240^{\circ} . s^{-1}$ on $Q$ concentric dominant side $; 240 Q$ ndom $C: 240^{\circ} . s^{-1}$ on $Q$ concentric nondominant side $; 240 \mathrm{HdomC}: 240^{\circ} . \mathrm{s}^{-1}$ on H concentric dominant side ; $240 \mathrm{HndomC}: 240^{\circ} . \mathrm{s}^{-1}$ on H concentric non-dominant side; $30 H d o m E: 30^{\circ} . \mathrm{s}^{-1}$ on H eccentric dominant side ; 30HndomE : $30^{\circ} . s^{-1}$ on H eccentric non-dominant side; ** : $p<0.01 ; * * *: p<0.001$. 


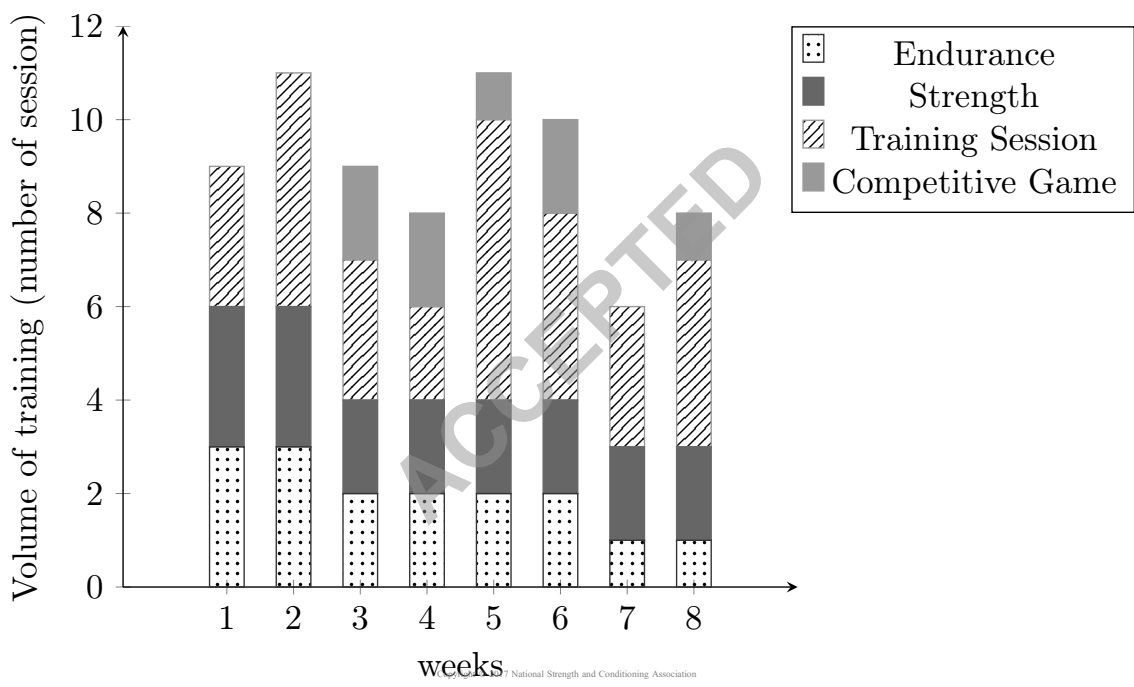

